\title{
Should Monetary Policy Use Long-Term Rates?
}

\author{
Mariano Kulish \\ Boston College
}

November 21, 2005

\begin{abstract}
This paper studies two roles that long-term nominal interest rates can play in the conduct of monetary policy in a New Keynesian model. The first allows long-term rates to enter the reaction function of the monetary authority. The second considers the possibility of using long-term rates as instruments of policy. It is shown that in both cases a unique rational expectations equilibrium exists. Reacting to movements in long yields does not improve macroeconomic performance as measured by the loss function. However, long-term rates turn out to be better instruments when the relative concern of the monetary authority for inflation volatility is high.
\end{abstract}

*I am indebted to Peter Ireland for his help and support. I also wish to thank, Pierluigi Balduzzi, Kit Baum, David Belsley, Fabio Ghironi, Chris Kent, Kristoffer Nimark, Glenn Rudebusch, Fabio Schiantarelli, Richard Tresch and participants at the Dissertation and Monetary Economics Seminars at Boston College for helpful comments. All errors are my own.

$\dagger$ This paper is based on Chapter 2 of my doctoral dissertation, "Money, interest rates, and monetary policy", at Boston College.

$\ddagger$ Please address correspondence to: Mariano Kulish, Economic Research, Reserve Bank of Australia, GPO Box 3947, Sydney, 2001, NSW, Australia, T: (61) 295518841 E: kulishm@rba.gov.au 


\section{Introduction}

Long-term interest rates play a central and potentially important role in the conduct of monetary policy. On the one hand, the transmission mechanism of monetary policy is traditionally perceived as going from a short-term nominal interest rate, assumed in general to be the instrument of monetary policy, to a long-term real interest rate that influences aggregate demand. On the other hand, there have been proposals involving the explicit use of nominal long-term interest rates for the conduct of monetary policy. The goal of this paper is to study two potential ways in which central banks can use long-term nominal interest rates to implement monetary policy: a) reacting to longterm rates, and b) setting long-term rates.

a) Reacting to long-term rates.

Federal Reserve policy-makers have recently come to rely on long-term nominal interest rates to measure the private sector's long-term inflationary expectations. The Fisher decomposition reveals that two terms are crucial for the equilibrium determination of nominal interest rates: an expected real rate and an expected inflation term. Hence, a monetary authority that desires to keep inflation under control might be interested in the use of reaction functions for monetary policy that incorporate long-term yields as arguments, as long as the predominant force moving long-term yields is the expected inflation term. In fact, Ireland's (1996) statistical results suggest that this is the main force responsible for most of the movements observed in U.S. long-term yields. Therefore, monetary policy makers are well justified to interpret movements in longterm rates as reflecting underlying movements in long-term inflationary expectations. Goodfriend (1993) has convincingly argued that in order to establish and maintain credibility during the period 1979 to 1992, the Federal Reserve reacted to the infor- 
mation in long-term nominal interest rates about long-term inflationary expectations. Additionally, McCallum (1994) has shown that a monetary policy rule that responds to the prevailing level of the spread between a long-term rate and a short-term rate can rationalize an important empirical failure of the expectations hypothesis. ${ }^{1}$ Mehra (1996) and Mehra (1999) econometric results reveal that the federal funds rate reacted to movements in a long-term bond yield in the 1979-1997 period. ${ }^{2}$ The fact that changes in long-term yields help explain movements in the federal funds rate raises two important questions.

First, one can shown that the theory of the term structure that emerges from optimizing behavior is the expectations hypothesis. A monetary policy reaction function that includes a long-term rate immediately raises the question of whether or not a unique rational expectations equilibrium (REE) exists in this case. The question is important since the combined power of the expectations hypothesis and the proposed monetary policy rule might give rise to self-fullfiling prophecies in the determination of the yield curve. What are the conditions that guarantee uniqueness of the REE when the central bank's actions depend on the level of a long-term interest rate?

Second, assuming that the conditions that ensure a unique REE exist, is such an interaction between short-term and long-term interest rates desirable according to a standard loss function criterion? Which is the best maturity length for the monetary authority to react to?

\footnotetext{
${ }^{1}$ This failure is related to the magnitude of the slope coefficients in regressions of the short rate on long-short spreads. A partial equilibrium interpretation of the expectations hypothesis implies that the slope coefficient, $b$, in a regression of the form, $\frac{1}{2}\left(R_{1, t}-R_{1, t-1}\right)=a+b\left(R_{i, t}-R_{1, t-1}\right)+$ shock, should have a probability limit of 1 . Many empirical findings in the literature yield a value for $b$ considerably below 1. As shown by McCallum (1994) the expectations hypothesis is consistent with these findings if it is recognized that the term premium follows an exogenous random process and monetary policy involves smoothing of the instrument as well as a response to the level of the spread.

${ }^{2}$ Mehra (1999) measures the long-term bond rate by the nominal yield on 10-year U.S. Treasury bonds.
} 
To study these questions I propose a modification of a standard Taylor rule that adds a long-term rate as an additional variable to which the central bank adjusts its short-term rate. In the context of a standard New Keynesian model, I show that there are large and empirically plausible regions of the policy-parameter space where a unique REE exists when the central bank conducts policy in this manner. However, a sufficiently strong reaction to the level of a long-term rate might raise the important problem of indeterminacy. In addition, I find that reacting to movements in long-term rates does not improve the performance of the central bank, regardless of the maturity length in question.

b) Setting long-term rates.

Another potential use for long-term nominal interest rates is the possibility of using them as instruments of monetary policy. The current low levels of inflation experienced by developed economies in recent years have raised an important number of new challenges for the conduct of macroeconomic policy. Among these is the problem of whether long-run rates of inflation and levels of short-term nominal interest rates can get sufficiently low that monetary policy becomes ineffective in its attempts to combat an economic recession. This problem might occur if the instrument of monetary policy, assumed in general to be a short-term nominal interest rate, hits its lower bound of zero. Japan's recent economic downturn, in which overnight money-markets interest rates were virtually zero, together with the recently low levels of the federal funds rate in the U.S. has motivated an interest in the study of alternative monetary policy actions. Clouse et. al. (2003) review a number of alternative actions that the monetary authority might take in this case. Among the candidates is the possibility that the monetary authority intervenes in longer-term treasury securities markets. It 
is a well known stylized fact that the yield curve is usually upward sloping, suggesting the possibility of further stimulating aggregate demand through longer-term rates once short-term rates hit their zero bound. ${ }^{3}$ Additionally, intervention in long-term bond markets might influence expectations about the path of the short-term rate, and hence the path of future traditionally perceived policy.

Regardless of the zero bound problem, the possibility of using long-term rates as instruments of monetary policy in a formal monetary model has received surprisingly little attention in the literature, and this analysis seems interesting in its own right.

In this paper, I study equilibrium determinacy under policy rules that set a nominal interest rate other than the short-term rate, and show that, for reasonable parameter values, a unique REE exists. The normative results reveal that when the central bank is mainly concerned with inflation volatility, long-term rates perform better than the traditional short-term rate in the class of Taylor-type rules. ${ }^{4}$

McGough et. al. (2005) analyze related problems of the possibility of using a long-term interest rate as the policy instrument in a similar New Keynesian model. ${ }^{5}$ However, this paper is different in important ways. First, I address the properties of policy rules that incorporate long-term rates as additional variables to which the central bank can react to. Second, the analysis of determinacy focuses on more elaborate rules which make the derivation of analytical results infeasible, but which adds to our

\footnotetext{
${ }^{3}$ In fact, Hicks (1937, p. 155) states:

"In an extreme case, the shortest short-term rate may perhaps be nearly zero. But if so, the longterm rate must lie above it, for the long rate has to allow for the risk that the short rate may rise during the currency of the loan, and it should be observed that the short rate can only rise, it cannot fall."

However, it is not clear in practice if further stimulation of aggregate demand would be possible through long-term rates at the zero bound.

${ }^{4}$ The analysis is done on a normal environment as opposed to a liquidity trap setting. A formal study of the possibility of getting around a liquidity trap by using long-term rates is outside the scope of this paper, and is left as a topic for future research.

${ }^{5} \mathrm{My}$ analysis is independent and contemporaneous to their own.
} 
understanding of long-term interest rate instruments. Third, I conduct a normative evaluation of these policy proposals.

One might initially suspect that a unique REE will not arise if the central bank decides to set, for instance, a two-period nominal interest rate. The reason is that, if the central bank wishes to set the two-period interest rate in a context in which the expectation hypothesis holds true, then there will exist infinite combinations for the one-period interest rate that satisfy the central bank's setting of the two-period rate. Notice that abstracting from a term premium and default risk, the two-period rate is an average of today's one-period rate and today's expectation of the one-period rate tomorrow. Interestingly, as shown below, this suspicion turns out to be incorrect.

In the context of the New Keynesian model the long-term real interest rate matters through the influence it exerts on aggregate demand. Under these two potential uses for long-term nominal rates, the long-term real rate continues to be the relevant rate for aggregate demand, but longer-term nominal interest rates now have an effect on the way shocks are propagated throughout the economy.

The rest of the paper is organized as follows. Section 2 presents the version of the standard New Keynesian model used here. Section 3 discusses determinacy of the REE under the proposed monetary policy rules as well as their implications for the dynamic behavior of the economy. Section 4 studies the problem of optimal monetary policy and establishes whether or not, under the proposed calibrations, long-term rates should be used. Section 5 summarizes the main results of the paper and concludes by suggesting potential avenues for future research. 


\section{The New Keynesian Model}

The model presented here is a standard New Keynesian model with an extended set of equilibrium conditions in order to allow for an explicit consideration of the term structure of interest rates. Instead of working through the details of the derivation, I present the key aggregate relationships. ${ }^{6}$

If we let $x_{t}$ stand for the output gap, then the aggregate demand curve makes the current level of the output gap depend on the expected future level of the output gap and the one-period real interest rate.

$$
x_{t}=-\left(R_{1, t}-E_{t} \pi_{t+1}\right)+E_{t} x_{t+1}+\mu_{g}(1-\phi) g_{t}-(1-\rho) a_{t}
$$

In the equation above, $R_{1, t}$ stands for the one-period nominal interest rate, $\pi_{t}$ stands for the inflation rate during period $t, a_{t}$ is a technology shock with persistence governed by $\rho$, and $g_{t}$ is a preference shock with persistence governed by $\phi$ and size $\mu_{g}$.

It can be shown that the theory of the term structure of interest rates that emerges from optimizing behavior in the context of this model is the expectations hypothesis. The nominal interest rate at $t$ associated with a zero-coupon bond that promises to pay one dollar at the end of period $t+i-1$ is given by,

$$
R_{i, t}=\frac{1}{i} E_{t} \sum_{k=1}^{i} R_{1, t+k-1}, \forall i \geq 2
$$

Firms are assumed to operate in an environment characterized by monopolistic competition in the goods market and by price stickiness. Factor markets are assumed

\footnotetext{
${ }^{6}$ See Clarida, Gali and Gertler (1999), Ireland (2004), Woodford (2003) and Yun (1996) for a more detailed discussion of the New Keynesian model.
} 
to be competitive and goods are produced with a constant returns to scale technology. Following Calvo (1983), it can then be shown that the above assumptions produce the log-linear New Phillips curve given by,

$$
\pi_{t}=\lambda x_{t}+\beta E_{t} \pi_{t+1}+\mu_{v} v_{t}
$$

where $v_{t}$ is a cost-push shock with size $\mu_{v}$ and with persistence given by $\theta$. The parameter $\lambda>0$ governs how inflation reacts to movements of output from its natural level. A larger value of $\lambda$ implies that there is a greater effect of output on inflation. In this sense, prices may be viewed as adjusting faster. The household's discount factor $\beta$ is restricted to lie between 0 and 1.

Finally to close the model, we need assumptions about the behavior of the monetary authority. The standard case characterizes monetary policy as a commitment to the following Taylor-type rule,

$$
R_{1, t}=\tau R_{1, t-1}+\alpha \pi_{t}+\delta x_{t}+\mu_{b} b_{t}
$$

where $b_{t}$ is a monetary policy shock whose size is governed by $\mu_{b}$.

In the case in which the monetary authority adds a long-term rate as an additional variable to which it reacts, policy is characterized by,

$$
R_{1, t}=\tau R_{1, t-1}+\alpha \pi_{t}+\delta x_{t}+\gamma R_{i, t}+\mu_{b} b_{t}
$$

Throughout the paper, policy rules that allow a reaction to long-term rates will be called type-1 rules. I study policy rules of type-1 for maturities 2, 4, 12, 20 and 40, which for a quarterly frequency, corresponds to a term structure composed of bonds 
with maturities 6 months, 1 year, 3 years, 5 years and 10 years respectively.

When the central bank uses a long-term rate as the operating instrument, monetary policy follows a rule of the form,

$$
R_{i, t}=\tau R_{i, t-1}+\alpha \pi_{t}+\delta x_{t}+\mu_{b} b_{t}
$$

Policy rules for which the instrument of monetary policy is other than the short-term rate will be labeled type- 2 rules. Notice that the equation above is similar to a standard Taylor-rule except for the interest rate that is being set by the central bank. As before, the selected term structure for type-2 rules is $2,4,12,20$ and 40 .

Notice that as interest rates of various maturities are linked by the expectations hypothesis, whatever outcome a type- 1 or type- 2 rule produces, it could alternatively be obtained using some given rule for the short-term rate. For example, the central bank could achieve the same equilibrium allocation either by using a type- 2 rule for $R_{2, t}$, or by using a rule for the short-term of the form,

$$
R_{1, t}=\tau R_{1, t-1}+\tau E_{t-1} R_{1, t}-E_{t} R_{1, t+1}+2 \alpha \pi_{t}+2 \delta x_{t}+2 \mu_{b} b_{t}
$$

Hence, one could view the exercise as an analysis of different policy rules for the short rate, or as a comparison of Taylor-type rules involving longer-term rates. 
Finally the stochastic block of the model is assumed to behave as given by,

$$
\begin{aligned}
& a_{t}=\rho a_{t-1}+\epsilon_{t}^{a} \\
& b_{t}=\epsilon_{t}^{b} \\
& g_{t}=\phi g_{t-1}+\epsilon_{t}^{g} \\
& v_{t}=\theta v_{t-1}+\epsilon_{t}^{v}
\end{aligned}
$$

where the parameters are restricted as follows: $|\rho|<1,|\phi|<1,|\theta|<1$, and the shocks $\epsilon_{t}^{a}, \epsilon_{t}^{b}, \epsilon_{t}^{g}$ and $\epsilon_{t}^{v}$ are assumed to be i.i.d. with normal distributions, zero mean and standard deviations given by, $\sigma_{\epsilon^{a}}, \sigma_{\epsilon^{b}}, \sigma_{\epsilon^{g}}$, and $\sigma_{\epsilon^{v}}$ respectively.

The model is calibrated as follows. The parameters $\beta$ and $\lambda$ are fixed throughout the study. These parameters are set to 0.99 and 0.14 respectively, as usually done in the literature. The value for $\lambda$ implies an expected price-contract length of one year. ${ }^{7}$ The parameters governing the behavior of the exogenous variables, $\rho, \phi, \theta, \mu_{b}, \mu_{g}$ and $\mu_{v}$ are not relevant for assuring a unique equilibrium. ${ }^{8}$ However the dynamics and volatility of the economy are in fact affected by the size and persistence of the shocks that hit the system. Following Cooley and Prescott (1995), $\rho$ is set equal to 0.95 and the standard deviation of the technology shock, $\sigma_{\epsilon^{a}}$, is set to 0.7 expressed in percentage terms. The shocks associated with the parameters $\phi$ and $\theta$ are known in the literature

\footnotetext{
${ }^{7}$ It can be shown using the full blown model that $\lambda=(1-\varphi)(1-\beta \varphi)(1+\eta) / \varphi$. Here $\varphi$ is the parameter that governs the degree of price stickness and $\eta$ the parameter that governs the elasticity of labor supply. The value of $\eta$ is set to 0.6 as suggested by Greenwood, Hercowitz and Huffman (1988) so as to match microeconometric estimates of labor supply elasticities. An expected price-contract length of one year implies a value of 0.75 for $\varphi$.

${ }^{8}$ Since these parameters do not enter the $\mathbf{K}$ matrix, the eigenvalues of $\mathbf{K}$ are not functions of their values. Strictly speaking, it is required that expectations of $\mathbf{v}_{t+k}$ (the vector of exogenous variables) do not grow exponentially or explode too fast. My calibration satisfies this requirement. See Blanchard and Kahn (1980) for details.
} 
to be highly persistent innovations. ${ }^{9}$ For this reason their values will be set to 0.95 and 0.95 respectively. Finally the parameters that control the size or standard deviation of the remaining shocks are calibrated as follows: in the standard case with $\tau=0.5$, $\alpha=0.6$ and $\delta=0.0009$, the values of $\mu_{b}, \mu_{g}$ and $\mu_{v}$ are chosen so as to match the volatility of the output gap, the interest rate and inflation in the data. ${ }^{10}$ The output gap is constructed as the log difference between the seasonally adjusted quarterly real GDP and real potential quarterly GDP taken from the U.S. Congress: Congressional Budget Office. Inflation is measured as the quarterly change of the GDP Implicit Price Deflator and the interest rate is taken to be the 3-month Fama and Bliss zero-coupon bond yield from the CRSP data.

\section{$3 \quad$ Equilibrium Determinacy}

Under appropiate identifications, the model could be written in matrix form as,

$$
E_{t} \mathbf{s}_{t+1}=\mathbf{K} \mathbf{s}_{t}+\mathbf{L} \mathbf{v}_{t}
$$

where: $\mathbf{s}_{t}=\left(\begin{array}{ll}\mathbf{z}_{t}^{\prime} & \mathbf{p}_{t}^{\prime}\end{array}\right)^{\prime}, \mathbf{z}$ is an $(m \times 1)$ vector of predetermined variables at $t ; \mathbf{p}$ is an $(n \times 1)$ vector of non-predetermined at $t$; and $\mathbf{v}$ is an $(k \times 1)$ vector of exogenous variables.

Let $\bar{n}$ be the number of eigenvalues of $\mathbf{K}$ outside the unit circle. We then have the following three cases. If $\bar{n}=n$ then there is a unique equilibrium solution. If $\bar{n}>n$ then an equilibrium solution does not exist, and if $\bar{n}<n$ then there is an infinity of

\footnotetext{
${ }^{9}$ See Ireland (2004).

${ }^{10}$ Hence $\sigma_{\epsilon^{b}}, \sigma_{\epsilon^{g}}$, and $\sigma_{\epsilon^{v}}$ are set to 1 .
} 
equilibrium solutions. ${ }^{11}$

As the reader might appreciate, the study of uniqueness becomes analytically intractable, specially as we move towards larger maturities. For this reason, I resort to a numerical study of the problem. Nevertheless, as shown below, interesting numerical patterns emerge from this study.

\subsection{Type-1 Rules: Reacting to long-term rates}

In this subsection I study the conditions that support a unique REE for the class of type- 1 rules given by $R_{1, t}=\tau R_{1, t-1}+\alpha \pi_{t}+\delta x_{t}+\gamma R_{i, t}$. Figure 1 shows the regions of uniqueness for given values of $\tau$ and $\delta$ in $\alpha-\gamma$ space. $^{12}$ A number of interesting features of this type of policy rule are worth highlighting. Notice that the critical contour, for which the crucial eigenvalue of the $\mathbf{K}$ matrix is one, has a downward and an upward sloping part in each case. The downward sloping portion of the contour reveals that there is a substitution, in terms of assuring a unique equilibrium, between the reaction to current inflation, $\alpha$, and the reaction to the long-term nominal interest rate, $\gamma$. Further numerical exploration shows that in the downward sloping part of the contour, a condition of the form $(\tau+\alpha+\gamma>1)$ is necessary for determinacy, regardless of the maturity length in question. Note that the Taylor-principle $(\alpha+\tau>1)$, that the short-term rate must rise in the long-run sufficiently in response to movements in inflation to increase real rates, no longer holds in this case. The upward sloping section of contour shows that as $\gamma$ becomes 'too large', the policy rule is unable to produce a unique outcome. The intuition behind this result is the following. For simplicity

\footnotetext{
${ }^{11}$ See Blanchard and Kahn (1980) for a detailed presentation.

${ }^{12}$ Figure 1 shows regions of uniqueness for $R_{4}, R_{12}, R_{20}$, and $R_{40}$. The regions for $R_{2}$ are not much different and were left out due to the usual limitations. An earlier version of the paper contains figures for $R_{2}$ as well.
} 
take the two-period rate and notice that it could be written, according to the Fisher decomposition, as follows

$$
R_{2, t}=\frac{1}{2} E_{t}\left(x_{t+2}-x_{t}+\sum_{k=1}^{2} \pi_{t+k}\right)
$$

The above expression shows that by reacting to the two-period rate, the monetary authority is implicitly reacting to the average expected path of inflation in the following two periods. This explains why the Taylor-principle is modified to a condition of the form $(\alpha+\tau+\gamma>1)$ in the downward sloping part of the contour. In this sense there is a substitution for assuring a unique equilibrium between the reaction to the long-term rate and current inflation.

To gain intuition about the upward sloping portion of the contour, recall that, according to the expectations hypothesis, we may alternatively write $R_{2, t}$ as,

$$
R_{2, t}=\frac{1}{2}\left(R_{1, t}+E_{t} R_{1, t+1}\right)
$$

The problem is that a 'too large' value of $\gamma$ allows self-fulfilling expectations to take place. To see why, observe that expectations that interest rates will be high become self-fulfilling, because the expectations of high short-term rates in the future causes long-term rates to rise, leading the monetary authority to raise short-term rates. Thus, in this case the monetary authority validates the initial expectation that short-term rates will be high. The upward sloping part of the contour shows that there is a complementarity between $\alpha$ and $\gamma$. In this region, a higher value of $\gamma$ requires a stronger connection between the short-term rate and inflation in order to avoid self-fulfilling expectations from happening. It is precisely in this respect that the Taylor-principle 
breaks down for type-1 rules.

Further numerical exploration shows that in the upward sloping part of the contour, higher values of $\tau$ and $\delta$ permit, for a given value of $\alpha$, a higher value of $\gamma$. Notice that the Fisher decomposition implies without loss of generality that reacting positively to $R_{2}$ is equivalent to an implicit negative reaction to the current output gap. To see this consider (5), the type-1 policy rule with $i$ equal to 2 and rewrite it with the help of the Fisher decomposition as,

$$
R_{1, t}=\tau R_{1, t-1}+\alpha \pi_{t}+\frac{\gamma}{2} \sum_{k=1}^{2} E_{t} \pi_{t+k}+\left(\delta-\frac{\gamma}{2}\right) x_{t}+\frac{\gamma}{2} E_{t} x_{t+2}
$$

Hence, higher values of $\delta$ allow for higher values of $\gamma$ without implying a negative reaction to the current output gap. ${ }^{13}$

Figures 1 reveals that as we move towards policy rules that involve larger maturity rates, the upward sloping region of the critical contour increases its slope. So, for a given value of $\alpha$ it is necessary a higher value of $\gamma$, the longer the interest rate, to produce multiple solutions. The fact that the interest rates in the policy rule are further apart in terms of maturity explains this result. Recall that expectations that shortterm interest rates will be high become self-fulfilling, because the expectation of high short-term rates in the future causes long-term rates to rise. When monetary policy reacts to very long-term rates, self-fulfilling expectations require that the response of the short-term rate to this movement be sufficiently strong so as to feed through the term structure with enough strength to move this very long-rate in a self-validating manner. So, as a stylized numerical observation, if the condition $\tau+\alpha+\gamma>1$ is

\footnotetext{
${ }^{13}$ It can be shown in the context of the standard case (i.e with a policy rule of the form $R_{1, t}=$ $\left.\tau R_{1, t-1}+\alpha \pi_{t}+\delta x_{t}\right)$ that under the proposed calibration of the model, in particular $\lambda=0.14$, for $\alpha>1$, there are multiple solutions so long as $\delta<0$.
} 
satisfied, for given values of the other parameters, the larger the maturity of the longterm rate in a type- 1 rule, the larger the value of $\gamma$ that supports a unique solution of the system. Mehra's (1999) GMM estimates yield a value of $\gamma$ of 0.46 in the case of the 10 year bond for the 1979-1998 period. Together with the other parameter estimates, the numerical exercise here suggests that monetary policy in the U.S. has not reacted to movements in the long-term rate so as to give rise to self-fullfilling fluctuations.

Up to this point I have shown that there are large and empirically plausible regions of the parameter space for which type-1 rules yield a unique REE. Why should uniqueness be a desirable property of any policy rule? Rules that support multiple solutions are problematic. The mere fact that such a rule may be consistent with a potentially desirable equilibrium is of little importance if it is also equally consistent with other, much less desirable equilibria. A rule that implies indeterminacy is consistent with a large set of equilibria, including ones in which the fluctuations in endogenous variables are arbitrarily large relative to the size of fluctuations in the exogenous shocks. ${ }^{14}$ In general, the variables for which there may be arbitrarily large fluctuations due to self-fulfilling expectations include those that enter the loss function of the monetary authority. Hence at least some of the equilibria consistent with the rule are less desirable, in terms of the loss function, than the unique equilibrium associated with any rule that guarantees a unique solution. For these reasons, the normative analysis restricts its attention to rules that imply a unique equilibrium. The question of whether or not type- 1 rules that yield a unique solution are at all desirable is taken up in section 4 .

\footnotetext{
${ }^{14}$ See Bernanke and Woodford (1997) for a formal description of a "sunspot" equilibrium. See also Woodford (2003, chapter 4).
} 


\subsection{Type-2 Rules: Long-term rates as instruments}

Here I study the conditions under which a unique REE exists for the class of rules given by $R_{i, t}=\tau R_{i, t-1}+\alpha \pi_{t}+\delta x_{t}$. Recall that in this case, a longer term interest rate is treated as the instrument set by the monetary authority.

Figure 2 shows the regions in $\alpha-\delta$ space in which a unique REE exists for $\tau=1 / 2$. As can be observed, significantly large regions of the parameter space exist that produce a unique REE. ${ }^{15}$ Notice that the regions of determinacy in the positive quadrants remain unchanged whatever the term of the interest rate chosen as instrument. Interestingly, Figure 2 also shows that, in the positive quadrants, the Taylor-principle holds for the selected value of $\tau$. Notice that $\alpha+\tau>1$ is required for determinacy in these cases. Although the numerical exercise so far suggests that the Taylor-principle generalizes to maturities other than one, this is true only in some regions of the policyparameter space. Further exploration in $\alpha-\tau$ space shows that the Taylor-principle eventually breaks down for longer term instruments, by displaying an upward sloping section of the critical contour. This complementarity between $\alpha$ and $\tau$ shows up for sufficiently positive values of $\delta$. Interestingly, in the standard case in which the policy instrument is the short-term rate, the critical contour's slope is always negative one with its equation given by $\tau=1-\alpha .^{16}$

The general result that a unique REE exists when the monetary authority sets an interest rate of maturity other than one is surprising in light of the intuition previously mentioned. Consider for example the case in which the central bank decides to set the two-period interest rate. One might initially believe that a unique equilibrium would

\footnotetext{
${ }^{15}$ McGough, Rudebusch, and Williams (2004) too found regions of uniqueness for a simple policy rule with a long-term rate instrument in a relatively similar environment.

${ }^{16}$ An earlier version of the paper contains figures in $\alpha-\tau$ space that illustrate this result.
} 
not arise in this case since the expectations hypothesis of the term structure suggests that infinite combinations of the short-term rate would satisfy the bank's setting of $R_{2}$. In fact recall that the expectations hypothesis says that the two-period rate is determined by $R_{2, t}=\frac{1}{2}\left(R_{1, t}+E_{t} R_{1, t+1}\right)$. At first sight, one chosen value for $R_{2, t}$ could be achieved by infinitely many paths for $R_{1}$, so that uniqueness could not be achieved. Clearly the results show that this is not the case in large and plausible regions of the parameter space. To gain intuition why a unique outcome can obtain even when the central bank decides to set a longer term rate consider the following. Loosely speaking, the expectations hypothesis of the term structure says that long-term rates are determined by the expected future path of the short-term rate during the maturity horizon in question. Thus, we generally think that short-term rates determine the level of long-term rates. However, it is important to realize that the expectations hypothesis works in the opposite direction as well. In fact, it does not place a restriction as to a direction of determination for interest rates. To see this formally consider the equation for $R_{2}$ and rewrite as a first order stochastic difference equation in $R_{1}$,

$$
R_{1, t}=-E_{t} R_{1, t+1}+2 R_{2, t}
$$

Advance the equation one period and substitute it back to obtain,

$$
R_{1, t}=2 R_{2, t}-2 E_{t} R_{2, t+1}+E_{t} R_{1, t+2}
$$

Repeating this operation many times and using the fact that $\lim _{j \rightarrow \infty} E_{t} R_{1, t+j}=0$ yields,

$$
R_{1, t}=2 \sum_{j=0}^{\infty}(-1)^{j} E_{t} R_{2, t+j}
$$


Equation (10) uncovers why the previous intuition is incorrect. A uniquely expected path for the two-period rate, as given by (10), determines in a unique manner the current level of the one-period rate. It can be shown that the general expression of the relevant path to be followed for an interest rate of maturity $i$ in order to determine the current level of the one-period nominal rate is given by,

$$
R_{1, t}=i\left(\sum_{j=0}^{\infty} E_{t} R_{i, t+i j}-\sum_{j=0}^{\infty} E_{t} R_{i, t+i j+1}\right)
$$

Equation (11) generalizes the argument for interest rates of any term. Thus, whatever the maturity of the interest rate chosen as instrument, if the monetary policy rule implies a unique outcome, then the uniquely expected path of the instrument uniquely determines the current level of interest rates of longer as well as shorter maturities.

The result that uniqueness arises even when the central bank decides to use an interest rate other than the short-term rate for a policy rule of the Taylor-type is important for several reasons. On a somewhat subtle level, it provides support for the theoretical study of macro-monetary models at various frequencies without implying any kind of hidden inconsistency. Without taking a stand on whether time is continuos or discrete, it should almost go without saying that real world economics occurs at (at least) a daily frequency. Discrete models in monetary economics are generally studied at a quarterly frequency without an explicit concern on whether or not the theoretical short-term rate (a 3-month rate), would imply a unique level of the current overnight rate. Although models are usually studied at a quarterly frequency, sometimes calibration is done at a monthly or annual frequency. The result presented here provides a theoretical foundation for such frequency choices.

This result might also be of practical importance in light of the zero-bound prob- 
lem. The fact that a unique equilibrium exists for longer term rate as instruments of policy, suggests an interesting potential solution. Since the level of long-term rates is generally above the level of short-term rates monetary policy might be able to further stimulate aggregate demand through longer term rates once short-term rates hit their zero bound. ${ }^{17}$ However, this is only potentially so, and further research would be necessary to address this possibility. ${ }^{18}$ In the context of the model used here interest rates are linked mechanically through the pure expectations hypothesis. If monetary policy is not constrained to a parametric set of rules, then any interest rate could achieve the same outcome as any other. However, in practice I would suspect that additional complexities might make long-term rates useful instruments at the zero-bound. In particular, altering the level of longer-term rates might have an impact on the composition of risk premia which may directly influence private sector decisions in long-term interest rate sensitive sectors of the economy. However this is mere speculation since little is known about the precise way in which monetary policy interplays with the composition and distribution of risk.

Without any reference to the zero-bound problem, the result opens up a new dimension of analysis for monetary policy rules that is interesting in its own right. Namely, which interest rate, among a given class of rules, performs best? Which interest rate instrument gets closer to the robustly optimal monetary policy rule in the sense of Giannoni and Woodford (2002)? The next section addresses these questions.

\footnotetext{
${ }^{17}$ In fact, Fed Chairman Alan Greenspan said (in a context in which the federal funds rate was at a 41-year low of $1.25 \%$ ) that in addition to pushing the funds rate, the interest rate that banks charge each other on overnight loans, closer to zero, the Fed can simply begin buying longer-term Treasury securities to drive longer-term interest rates lower. -Associated Press Newswires, May 21, 2003.

${ }^{18}$ See Woodford (2005) for a discussion of additional complications that might arise when using long-term rates as instruments of policy.
} 


\subsection{Dynamics}

I have previously shown that large regions of uniqueness exist for type-1 and type-2 rules. Given this fact, what are the dynamic implications associated with these rules? In other words, it seems interesting to study the way in which the economy responds to shocks under representative type-1 and type-2 rules versus a standard Taylor rule. Figures 3 illustrates this comparison by displaying the impulse responses of inflation and output to a monetary-shock and a cost-push shock for a standard Taylor rule, and for type- 1 and type- 2 rules involving $R_{12}$ and $R_{40}$ respectively. Notice that the parameters remain fixed across rules in order to capture the effects implied by the maturity dimension of the problem. A number of interesting features arise from this comparison. In the first place, notice that the signs of the responses do not change across policies. The qualitative responses of inflation and the output gap are the same as those generated by a standard Taylor rule. A contractionary monetary policy shock reduces on impact both inflation and the output gap for all rules considered, while an adverse cost-push shock increases inflation and decreases output on impact for all rules as well. These results suggest that type-1 and type-2 rules do not imply 'strange' responses to the disturbances that hit the economy. Secondly, observe that the size of the responses is significantly affected by the type of policy rule. In fact, notice that in the case of type- 1 rules in response to a cost-push shock, inflation deviates less than in the standard case while output suffers a bigger contraction. A similar result shows up in the case of type-2 rules in response to an adverse cost-push shock. In this case, note that the maturity length of the instrument matters for the determination of the trade-off between output and inflation deviations from the steady state. Finally, Figure 3 shows that a contractionary monetary shock implies a bigger contraction for 
inflation and output the longer the maturity of the instrument interest rate. This arises because the size of the monetary shock in fact changes across policy rules. That is, a one-standard deviation of $b_{t}$ attached to a type- 2 rule for $R_{40}$ raises the one-period nominal interest rate by more than a one-standard deviation of $b_{t}$ in a standard Taylor rule. For this reason the size of the monetary policy shock, $\mu_{b}$, is set to zero in all policy rules for the normative analysis. ${ }^{19}$

As shown, the impulse responses suggest that the dynamic behavior of the economy is significantly affected by the choice of policy rule. In fact, different rules imply a distinct trade-off between inflation and output deviations in response to a cost-push shock. This shock plays a key role in the conduct of monetary policy. It presents the monetary authority with a trade-off between output and inflation stabilization. The fact that quantitatively different responses are observed under different rules motivates the question of what monetary policy rule does best for the central bank. The next section addresses this question.

\section{Optimal Monetary Policy Rules}

I start by constructing a robustly optimal policy rule following Giannoni and Woodford (2002). I consider a rule that would bring about the optimal equilibrium pattern of responses to shocks as well as yield a unique stationary equilibrium for the economy. I assume that the objective of the monetary authority is to minimize the expected value

\footnotetext{
${ }^{19}$ This guarantees that the comparison between policy rules is 'fair' in the sense of capturing only the impact of the deterministic component.of the rules.

However, this highlight an important fact. If there is inherent randomness in the conduct of monetary policy, long-term rates might be undesirable instruments because they magnify the effects of monetary policy shocks.
} 
of a loss criterium given by,

$$
J=\frac{1}{2} E_{0}\left(\sum_{t=0}^{\infty} \beta^{t} L_{t}\right)
$$

where the bank's discount rate $\beta$ is the same as in (3) and the period loss function is of the form,

$$
L_{t}=\pi_{t}^{2}+\omega_{x} x_{t}^{2}+\omega_{R} R_{1, t}^{2}
$$

Here the parameters $\omega_{x}$ and $\omega_{R}$ (assumed to be positive) govern the relative concern for output and short-term nominal interest rate variability. Hence, the monetary authority faces the problem of minimizing (12) subject to equations (1) and (3). Notice that minimization is achieved by choosing a time path for $\left\{\pi_{t}, x_{t}, R_{1, t}\right\}_{t=0}^{\infty}$ that minimizes the monetary authority's objective and simultaneously satisfies the model's structural equations at each point in time. The first order conditions of the problem are given by,

$$
\begin{aligned}
\pi_{t}-\beta^{-1} \Lambda_{1, t-1}+\Lambda_{2, t}-\Lambda_{2, t-1} & =0 \\
\omega_{x} x_{t}+\Lambda_{1, t}-\beta^{-1} \Lambda_{1, t-1}-\lambda \Lambda_{2, t} & =0 \\
\omega_{R} R_{1, t}+\Lambda_{1, t} & =0 \\
R_{1, t}-E_{t} x_{t+1}+x_{t}-E_{t} \pi_{t+1}-\mu_{g}(1-\phi) g_{t}+(1-\rho) a_{t} & =0 \\
\pi_{t}-\lambda x_{t}-\beta E_{t} \pi_{t+1}-\mu_{v} v_{t} & =0
\end{aligned}
$$

where $\Lambda_{1, t}$ and $\Lambda_{2, t}$ stand for the Lagrange multipliers associated with the IS and New Phillips curve equations respectively. One can use the equations above to substitute out the Lagrange multipliers in order to obtain a monetary policy rule consistent with 
the optimal allocation of the form,

$$
R_{1, t}=\left(1+\frac{\lambda}{\beta}\right) R_{1, t-1}+\frac{1}{\beta} \Delta R_{1, t-1}+\frac{\lambda}{\omega_{R}} \pi_{t}+\frac{\omega_{x}}{\omega_{R}} \Delta x_{t}
$$

As shown by Giannoni and Woodford (2002), commitment to this rule implies a unique equilibrium as well as an optimal equilibrium pattern of responses to the economy's disturbances. In this case, the optimization is not performed over some parametric set of policy rules (e.g. a Taylor-type rule). The approach in this case consists of characterizing the best possible pattern of responses to shocks by taking the structural equations as constraints, and then finding the policy rule that generates such an equilibrium.

Since taking into account only a set of monetary policy reaction functions rules out other possible kinds of feedback, any rule constrained to belong to a given set of rules cannot perform better than the rule that responds to shocks in the best possible way. Hence, type-1 or type-2 rules could not possibly yield a better outcome than (14). However, studying the degree to which these rules are optimal remains important for many reasons. Taking into account the McCallum's (1988) critique, namely, that the main problem that policymakers face is uncertainty about the exact structure of the economy, one realizes that this uncertainty would translate into uncertainty about the exact specification of the optimal monetary policy rule. For this reason it remains important to understand how a given rule works across different plausible environments. The exercise done here constitutes a step in this direction for type- 1 and type-2 rules. Simple policy rules have also been proposed on the basis of being operational and simple to communicate to the public. Operationality limits study of rules that are expressed in terms of instrument variables that could in fact be controlled by actual central banks 
and that require only information that could be possessed by these central banks. ${ }^{20}$ Although implementation of type-2 rules might require in some cases modifications in the legislation that applies to central banks, there is no a priori reason why central banks would not be able to manage policy by setting a longer term rate. In principle, a central bank with sufficient access to money balances (and large enough holdings of the asset in question) could stand ready to sell or buy a long-term bond at a desired target price. Different is the case for example of assuming that the monetary authority controls a monetary aggregate as M2 whose determination is not independent of the behavior of the private sector.

I therefore consider the optimal rule, (14), as a benchmark to evaluate the performance of type- 1 and type- 2 rules. I also take the standard case Taylor rule as a second benchmark of evaluation. I want to know which rule among the set of parametric policy rules given by (5) and (6) gets closer to the optimal rule. Do type-1 and/or type-2 rules imply gains relative to the standard Taylor rule? I will restrict attention to type-1 and type 2 rules that result in a unique stationary REE.

Table 1 shows, for different calibrations of $\omega_{x}$ and a value of 0.1 for $\omega_{R}$, the value of the loss function and each of its components for the optimal rule, (14), the standard rule, (4), and type-1 rules of the selected term structure. ${ }^{21}$ Reacting to movements in nominal longer-term rates does not present significant gains. As expected type-1 rules are no worse than the standard rule. In fact note that the standard rule is a

\footnotetext{
${ }^{20}$ If the central bank collects data with a lag, then depending on the frequency of the model, type2 rules might not be operational in practice. Notably McGough, Rudebusch and Williams (2005) address this problem and find regions of uniqueness for policies that set a longer term rate in response to lagged inflation.

${ }^{21}$ Notice that $\frac{1}{2} E_{0} \sum_{t=0}^{\infty} \beta^{t}\left(\pi_{t}^{2}+\omega_{x} x_{t}^{2}+\omega_{R} R_{1, t}^{2}\right)=\frac{1}{2(1-\beta)}\left(\sigma_{\pi}^{2}+\omega_{x} \sigma_{x}^{2}+\omega_{R} \sigma_{R_{1}}^{2}\right)$. So that minimizing $J$ is equivalent to minimizing a weighted average of the variances as given by $\frac{1}{2(1-\beta)}\left(\sigma_{\pi}^{2}+\omega_{x} \sigma_{x}^{2}+\omega_{R} \sigma_{R_{1}}^{2}\right)$. Since $\frac{1}{2(1-\beta)}$ is only a scaling constant, one can focus on the value of $\hat{J}=\sigma_{\pi}^{2}+\omega_{x} \sigma_{x}^{2}+\omega_{R} \sigma_{R_{1}}^{2}$ instead. This is the value of the loss function reported in all tables.
} 
particular case of a type- 1 rule for which $\gamma$ is set to zero. Inspection of Table 1 shows not only that type-1 rules achieve a value of the loss function which is identical to that of the standard rule, but also that the variances of the relevant variables remain unchanged. $^{22}$ Further numerical exploration shows that in the case of type-1 rules there are multiple parameter configurations that minimize the loss function. In general, for all calibrations and maturities considered the optimal value of $\gamma$ turns out to be negative. This is a surprising result in light of Goodfriend's (1993) account of monetary policy and Mehra's (1999) econometric results. Recall that the rationale for allowing the monetary authority to react to movements in long-term bond yields is that longterm nominal interest rates could measure the private sector's long-term inflationary expectations. The central bank might therefore be interested in using reaction functions that incorporate longer-term rates, so that if they rise the bank raises the short-term rate in its attempts to keep inflation under control. In other words, this behavior would imply a positive value of $\gamma$. Interestingly, there is a very recent macro-finance literature that includes the long-run expected inflation component of the long-term rate in the policy rule and can justify negative values for $\gamma \cdot{ }^{23}$

I find that there is a certain degree of substitution for optimality between the autoregressive coefficient, $\tau$, and the reaction to long-term rates, $\gamma$. Positively higher values of $\tau$ are associated with negatively smaller values of $\gamma$. Loosely speaking, longterm rates play a redundant role in the RHS of the policy rule. Recall that long-term rates could be expressed as the expected future path of $R_{1}$ over the maturity horizon

\footnotetext{
${ }^{22}$ This is in general true up to the 9 th decimal digit. A higher numerical precision shows that type- 1 rules are better than the standard rule as one would expect. However, this difference seems insignificant.

${ }^{23}$ For example, in response to a perceived decrease in the inflation target (a decrease in the expected inflation component of the long rate), the monetary authority must increase rates in order to push inflation down to this lower target. This behavior would justify a negative value of $\gamma$. See Rudebusch and $\mathrm{Wu}(2004)$
} 
in question. Therefore, reacting to movements in a longer-term rate is equivalent to reacting to the expected future path of the instrument in this case. To gain intuition, consider the case of a type- 1 rule for $i=2$ and rewrite it with the aid of (2) as

$$
R_{1, t}=\frac{2 \tau}{2-\gamma} R_{1, t-1}+\frac{2 \alpha}{2-\gamma} \pi_{t}+\frac{2 \delta}{2-\gamma} x_{t}+\frac{\gamma}{2-\gamma} E_{t} R_{1, t+1}
$$

Note that negative values of $\gamma$ imply (for $\tau>0$ ) a positive "backward-smoothing" coefficient and a negative "forward-smoothing" coefficient respectively. In addition, observe that the larger $\gamma$ is in absolute value the larger $\tau$ needs to be to yield a given value of the backward smoothing term. The fact that the autoregressive coefficient on $R_{1}, \frac{2 \tau}{2-\gamma}$, is the one that matters for the determination of expectations (in particular $\left.E_{t} R_{1, t+1}\right)$ explains why there are multiple pairs of $\tau$ and $\gamma$ that minimize the loss function. The expression above also reveals that in the context of type- 1 rules a sufficiently positive value of $\gamma$ would result in a negative reaction to the previous period short-term rate as well as to the current inflation rate and the current output gap.

Since there are no significant gains in reacting to movements in longer-term rates, I do not investigate any further the behavior of type-1 rules under alternative calibrations for $\omega_{x}$ and $\omega_{R}$.

Notice that a type- 1 rule is a modification of the familiar Taylor rule that adds a longer-term interest rate as another variable to which the central bank adjusts its short-term rate instrument. Elsewhere in the literature, others have proposed including other asset prices in the Taylor rule, such as stock prices and housing prices. As Filardo (2000) points out, Goodhart, a former member of the Bank of England's Monetary Policy Committee, argues that central banks should consider using housing prices and stock market prices to guide their policy decisions. Goodhart's recommendation 
is based on the argument that broader measures of inflation that include housing and stock market prices have the potential of improving macroeconomic performance if asset prices reliably predict future consumer price inflation. Goodhart's recommendation follows Alchein and Klein's (1973) view that traditional price indices are deficient because they consider only the price of goods consumed today. To the extent that long-term nominal interest rates capture future signs of inflation, my simulation results clearly suggest that such a reaction to long yields neither worsens nor improves macroeconomic performance relative to the standard Taylor rule (for which $\gamma$ is set to zero). One could conclude from this exercise that long-term nominal interest rates do not provide additional information for the monetary authority than what is already present in the lagged short-term interest rate, current output and current inflation. Filardo (2000) and Gilchrist and Leahy (2002) do not find a strong case for including asset prices in monetary policy rules as well.

Table 2 shows, for different calibrations of $\omega_{x}$ and a value of 0.1 for $\omega_{R}$, the value of the loss function and the value of each of its components for the optimal rule, (14), the standard rule, (4), and type-2 rules for the selected interest rates. Interestingly, medium and long-term rates perform better as instruments in the class of Taylor-type rules than short-term rates when the concern for output volatility is relatively low. For example note that when $\omega_{x}$ equals 0.05 , all instruments except $R_{40}$ do better than $R_{1}$. In this case, the best instrument turns out to be the 3 -year rate. Also note that a Taylor-rule with $R_{12}$ as the instrument, generates a lower variance for $R_{1}$ and higher variances for inflation and output relative to the optimal rule, but lower variances of inflation and output relative to the standard Taylor-rule. When the concern for output volatility increases to 0.1 , the optimal instrument for the class of Taylor-type rules, turns out to 
be the 5-year rate. Inspection of Table 2 reveals that in this case the relevant gain comes from the ability of $R_{20}$ to generate a lower variance of inflation. Observe that when $\omega_{x}$ equals $0.01,0.05$ and 0.1 (i.e when the concern for output deviations is relatively low) the volatility of the short-term rate increases as the maturity of the instrument increases. For these parameter values, using longer-term rates as instruments yields a higher variance of the short-term rate than that of the standard case. Notice however that this property is not preserved as the concern for output deviations increases to 0.33 or to 1 . Table 3 reproduces the results of Table 2 but this time with $\omega_{R}$ set to 1. Notice that as the concern for short-term variability increases the variance of $R_{1}$ diminishes as expected in all cases and for all the instruments. In Table 3, for all values of $\omega_{x}$ considered, the volatility of the short-term rate achieved by rules using longer-term rates is lower than in the optimal rule case and in the standard case. ${ }^{24}$ By comparing Tables 2 and 3 it can be observed that when the concern for output volatility is relatively low the optimal maturity length of the instrument is sensitive to the value of $\omega_{R}$. For example note, that when $\omega_{x}$ equals 0.1 and $\omega_{R}$ equals 0.1 , the best instrument turns out to be $R_{20}$. However, when $\omega_{x}$ equals 0.1 and $\omega_{R}$ equals 1 , the best instrument turns out to be $R_{12}$. Despite these differences in the maturity length, Tables 2 and 3 show an interesting pattern. When the relative concern for output volatility is low, medium/long-term rates perform better than the standard instrument and when the concern for output volatility is high the short-term rate turns out to be a

\footnotetext{
${ }^{24}$ This is in principle an interesting result in light of the liquidity trap problem. If one would find that in all the cases in which longer-term rates are used as instruments, the variance of the shortterm rate increases, then the potential solution of using longer-term rates when we approach the zero bound looses much of its appeal. Additionally as explained by Woodford (2003, chapter 6) it might be desirable in practice to pursue a policy that involves less volatility of the short-term nominal interest rate in the presence of large random disturbances than a policy that achieves complete price stability. The reason being that if disturbances are large in amplitude such a policy might not be possible because it might requiere the nominal interest rate to be negative at some times.
} 
better instrument. One of the main results of this section is that the optimal maturity length of the instrument depends upon the parameters determining the preferences of the monetary authority for the class of Taylor-type rules.

Both tables reveal the presence of two different kinds of trade-off between the volatility of inflation and the volatility of output. The first is the well known trade-off that arises when the parameter that governs the relative degree of concern for the output gap variance, $\omega_{x}$, varies. This trade-off is known in the literature as the Taylor curve. Notice that for all rules considered, as $\omega_{x}$ varies from 0.01 to 3 , the central bank manages to generate a lower variance for output at the expense of a higher one for inflation.

The second trade-off between the variance of output and the variance of inflation, which to the best of my knowledge is new in the literature, shows up in terms of maturities. Notice that a trade-off between the output and inflation variance appears for given values of $\omega_{x}$ and $\omega_{R}$ as we move along the maturity dimension of the instruments, for the class of standard/type-2 rules. Notice however that this is not a linear trade-off in all cases. For example, it is not always the case that when the maturity length of the instrument increases, one observes a lower variance of inflation at the expense of a higher one for output. However, it is generally the case, that each 'maturity movement' presents a trade-off between the two variances. ${ }^{25}$ Figure 4 illustrates this by plotting the loss function and its components against the maturity of the interest rate instrument. Panel A plots the case when $\omega_{x}$ equals 0.1 and $\omega_{R}$ equals 0.1 . Note that as the maturity of the instrument increases up to 20, the variance of inflation decreases and the variance of output increases, but as we move further into the term structure

\footnotetext{
${ }^{25}$ A note of caution is in place. Recall that I have selected a term structure composed of maturities $1,2,4,12,20$ and 40. Therefore, a 'maturity movement' means in this case a move from say 4 to 12. The calculations for intermediate maturities have not been done because of the usual limitations. However the general result that as we move along the term structure eventually a trade-off appears is preserved for the selected calibrations.
} 
the trade-off changes its direction. Panel B shows the case when the preferences of the central bank are given by $\omega_{x}$ set to 3 and $\omega_{R}$ set to 0.1 . Observe that this time the variance of inflation decreases and that of output increases but only up to a maturity of 4 . The direction of the trade-off changes above 4 . It is important to emphasize that this is a trade-off that emerges for given values of the parameters that govern the preferences of the monetary authority, $\omega_{x}$ and $\omega_{R}$. Also note that the precise nature of this trade-off changes when the preferences of the central bank change.

Notice that when the concern for inflation volatility is very high, the best instrument turns out to be the one-year interest rate. Why could this possibly be the case? In order to develop an intuition for this result notice that the expected price contract length is calibrated to one year. Further numerical exploration reveals that reducing the expected price contract length to 6 months yields the two-period rate as the best instrument when the concern for inflation variability dominates. Thus, I conjecture that when the concern for inflation volatility is high, the optimal maturity length of the instrument aligns to the degree of nominal rigidity in the economy. ${ }^{26}$

As an alternative way to understand the behavior of type- 2 rules I consider what happens to the loss function and its components as we deviate from the optimal value of one of the parameters in the policy rule. Figure 5 illustrates the case in which the reaction to current output, $\delta$, changes for the standard rule and type-2 rules with instruments given by $R_{12}$ and $R_{40}$, while the other parameters, $\tau$ and $\delta$, remain fixed at their optimal values. The situation is illustrated in the case of $\omega_{x}$ set to 3 and $\omega_{R}$ set to 0.1. Notice that a trade-off between the variance of output and the variance of inflation emerges as $\delta$ varies. Increasing $\delta$ results, for all rules, in a lower variance of

\footnotetext{
${ }^{26} \mathrm{~A}$ note of caution is in place. The parameter that governs the degree of price stickiness in the economy is $\lambda$. This parameter is not only a function of the expected price contract length, but also a function of the household's discount rate, and the elasticity of labour supply.
} 
output at the expense of a higher variance for inflation, as one would expect. However, the precise quantitative nature of the trade-off changes for different instruments. As $\delta$ increases from zero the variance of inflation achieved by rules with longer-term rates is smaller. The precise quantitative extent of the trade-off changes with the instrument. Note that the volatility of the short-term rate displays a trade-off with the volatility of output. Another interesting feature to note is that it seems relatively less costly to deviate from the optimal value of $\delta$ using $R_{12}$ as the instrument, as opposed to $R_{1}$ or $R_{40}$

The main message from this section is that it is not only possible to use longer-term nominal interest rates as instruments of policy within the class of Taylor-type rules, but it is also desirable under certain circumstances. In fact, there are plausible preferences for the monetary authority that make medium/long-term rates better instruments, by achieving a value for the loss function that gets closer to that of the optimal rule. I have also shown that a trade-off between the variances of output and inflation emerges in the maturity dimension. Hence, for given values of the parameters that determine the preferences of the central bank and among the class of Taylor-type rules, this new trade-off faces the monetary authority with a new dimension of choice, namely, the maturity length of the instrument.

\section{Conclusion}

In this paper I have studied the implications of using long-term nominal interest rates in the conduct of monetary policy. Under the first use for long-term rates the monetary authority is allowed to react to movements in some long-term yield. I have shown that there are plausible regions of the policy parameter space for which a unique stationary 
REE arises under such policy rules, labeled type-1 rules. The normative analysis has revealed that there are no significant gains from using type-1 rules in terms of reducing the value of the loss function. Surprisingly, the optimal parameter value of the reaction to long-term rates turns out to be negative in most cases, contradicting the initial intuition that recommends such use.

Under the second use for long-term nominal interest rates the monetary authority is allowed to conduct policy by virtue of a Taylor-type policy rule that sets a longerterm rate. The exercise conducted in this paper has revealed a number of surprising aspects of this proposal. Interestingly, significant regions of the policy parameter space exist where a unique stationary REE obtains. The numerical patterns show that the Taylor-principle, namely, that the long run reaction of the instrument to movements in inflation should exceed one, generalizes to instruments of various maturities in some regions of the parameter space. The general result that uniqueness arises for instruments other than the short-term rate is important in many dimensions. As emphasized previously, this result is of practical importance in light of the zero-bound problem. The existence of a unique equilibrium for longer term rates constitutes an interesting potential solution to the problem. A formal study of this possible solution involves a number of complications and constitutes an interesting avenue for further research. Regardless of the liquidity trap, longer-term rates may be better instruments in their own right for a given class of rule. The result opens up a new dimension of analysis for monetary policy rules. All the elements of the term structure emerge as potential candidate instruments for the conduct of monetary policy. This result also provides theoretical support for the study of macro-monetary models at various frequencies without implying a deeper inconsistency. Discrete models in macroeconomics are usually set at 
a quarterly or monthly frequency without an explicit concern on whether or not the theoretical short-term rate (a 3-month/1-month rate), would imply a unique level of the current overnight rate, which is what is typically assumed to be under the control of the central bank.

I then studied the performance of rules involving the explicit setting of a long-term rate and found that, for the class of Taylor-type rules, they are better instruments under certain central bank preferences. In particular, the exercise shows that when the relative concern for output variability is low, medium or long-term rates turn out to yield a better outcome. I have also found an interesting numerical pattern between the maturity of the instrument rate and the variances of output and inflation. Namely, for given preferences of the monetary authority, a trade-off between the variabilities of output and inflation emerges as we move through the term structure in our choice of instrument. This highlights one of the main results of the paper. That is, the choice of maturity length for the instrument is sensitive to the preferences of the central bank.

The results have opened up many interesting avenues for future research. Recall that the results are valid in the context of a simple New Keynesian model. It would therefore be interesting to study the robustness of these results in different economic environments. For example, are the main results preserved when investment and capital accumulation are included in the model? Are the results sensitive to different timing assumptions and different specifications of the Phillips curve? What happens in an open economy? What happens in alternative models of the monetary transmission mechanism (e.g. limited participation models)? Recently Andres et. al (2004) have extended the New Keynesian model by explicitly considering time-varying risk premia on longer term bonds and by introducing portfolio adjustment costs that give longer 
term rates a bigger role in the monetary transmission mechanism. It would therefore be of much interest to pursue in future work a study of the performance of type- 1 and type-2 rules in that extended environment.

One limitation of the exercise is that the analysis of alternative rules involving the explicit use of longer-term rates has been constrained to a selected term structure on the basis of being the empirically relevant one. However, it might well be the case that the optimal maturity of the instrument for a given class of rules is actually a 'hidden maturity'. Despite being an enormous numerical effort, a clearer understanding of the problem along the maturity dimension might be obtained by conducting the optimization over interest rates of all maturities.

In conclusion, the exercise conducted here has produced clear results. Long-term nominal interest rates can be used in alternative ways without implying the problems associated with multiple equilibria or non existence of an equilibrium solution, and under certain circumstances Taylor-type rules that set a longer-term rate better approximate the optimal outcome. 


\section{References}

1. Andres, J., J.D. Lopez-Salido, and E. Nelson (2004), "Tobin's Imperfect Asset Substitution in Optimizing General Equilibrium," The Journal of Money, Credit, and Banking, Vol. 36, No. 4, pp. 665-690

2. Blanchard, O. and Kahn, C. (1980), "The Solution of Linear Difference Models under Rational Expectations," Econometrica, Vol. 48, Issue 5, pp.1305-1312.

3. Bernanke, Ben S. and Michael Woodford (1997), "Inflation Forecasts and Monetary Policy," NBER Working Paper Series, WP 6157

4. Clarida, Richard, Jordi Galí, and Mark Gertler (1999): "The Science of Monetary Policy: A New Keynesian Perspective," Journal of Economic Literature 37: 16611707

5. Clouse, James, Dale Henderson, Athanasios Orphanides, David Small and Peter Tinsley (2003): "Monetary Policy When the Nominal Short-Term Interest Rate is Zero," Topics in Macroeconomics 2 (1)

6. Cooley, T. F., and E.C.Prescott (1995), "Economic Growth and Business Cycles," in Frontiers of Business Cycle Research, ed. T.F. Cooley, Princeton: Princeton University Press.

7. Eggertsson G. and Michael Woodford (2003), "The Zero Interest-Rate Bound and Optimal Monetary Policy," Presented at the Brookings Panel on Economic Activity, March 2003. www.princeton.edu/ woodford/

8. Filardo, A. (2000), "Monetary Policy and Asset Prices," Federal Reserve Bank of Kansas Economic Review, Third quarter. 
9. Giannoni, Marc and Michael Woodford (2002), "Optimal Interest-Rate Rules: General Theory," NBER Working Paper Series, WP 9419

10. Giannoni, Marc and Michael Woodford (2002), "Optimal Interest-Rate Rules: II Applications," NBER Working Paper Series, WP 9420

11. Gilchrist, S. and Leahy, J. V. (2002), "Monetary Policy and Asset Prices," Journal of Monetary Economics, Vol 49, pp. 75-97

12. Goodfriend, M. (1993), "Interest Rate Policy and the Inflation Scare Problem: 1979-1992," Federal Reserve Bank of Richmond Economic Quarterly Volume $79 / 1$.

13. Goodfriend, M., and King, R. (1997): "The New Neoclassical Synthesis and the Role of Monetary Policy," in Ben S. Bernanke and Julio J. Rotemberg (eds.), NBER Macroeconomics Annual 1997, Cambridge: MIT Press (with Olivier J. Blanchard's comments; link: Federal Reserve of Richmond WP version).

14. Goodfriend, M. (1998), "Using the Term Structure of Interest Rates for Monetary Policy," Federal Reserve Bank of Richmond Economic Quarterly Volume 84/3.

15. Goodfriend, M. (2000), "Overcoming the Zero Bound on Interest Rate Policy," Federal Reserve Bank of Richmond WP 00-3.

16. Greenwood, J. et. al. (1988), "Investment, Capacity Utilization, and the Real Business Cycle," American Economic Review, Vol. 78, pp. 402-417.

17. Hicks, J.R. (1937), "Mr. Keynes and the "Classics"; A Suggested Interpretation", Econometrica, Vol. 5, No.2, pp. 147-159. 
18. Ireland, P. (1996), "Long-Term Interest Rates and Inflation: A Fisherian Approach," Federal Reserve Bank of Richmond Economic Quarterly, Vol. 82, Issue 1.

19. Ireland, P. (2004), "Technology Shocks in The New Keynesian Model," Boston College Economics Department Working Paper 536.

20. King, R. (2000), "The New IS-LM Model: Language, Logic, and Limits," Federal Reserve Bank of Richmond, Economic Quarterly, Vol. 86, Issue 3.

21. Klein, Paul (2000), "Using the Generalized Schur Form to Solve a Multivariate Linear Rational Expectations Model," Journal of Economic Dynamics and Control 24, 1405-1423.

22. Krugman, Paul (1998), "It's Baaack: Japan's Slump and the Return of the Liquidity Trap," Brookings Papers on Economic Activity, Vol. 1998/2, 137-205.

23. McCallum, Bennett T. (1988), "Robustness Properties of a Rule for Monetary Policy," Carnegie-Rochester Series on Public Policy, 29, 173-204.

24. McCallum, Bennett T. (1994), "Monetary Policy and The Term Structure of Interest Rates," NBER Working Paper Series, WP 4938.

25. McGough, Bruce, Rudebusch, Glenn D., and John C. Williams (2005), "Using a Long-Term Interest Rate as the Monetary Policy Instrument," Journal of Monetary Economics, Vol. 52, 855-879

26. Mehra, Yash (1996), "Monetary Policy and Long-Term Interest Rates," Federal Reserve Bank of Richmond Economic Quarterly Volume 82/3 
27. Mehra, Yash (1997), "A Federal Funds Rate Equation," Economic Inquiry, Vol 35.

28. Mehra, Yash (1999), "A Forward-Looking Monetary Policy Reaction Function," Federal Reserve Bank of Richmond Economic Quarterly Volume 85/2

29. Rudebusch, G.D. and Tao Wu (2004), "A Macro-Finance Model of the Term Structure, Monetary Policy, and the Economy," Working Paper, Federal Reserve Bank of San Francisco.

30. Woodford, Michael (2005), Comment on: "Using a long-term interest rate as the monetary policy instrument," Journal of Monetary Economics 52, 881-887.

31. Woodford, Michael (2003), Interest and Prices: Foundations of a Theory of Monetary Policy, Princeton: Princeton University Press.

32. Yun, T. (1996), "Nominal Price Rigidity, Money Supply Endogeneity, and Business Cycles," Journal of Monetary Economics, Vol. 37, pp. 345-370. 
Figure 1: Regions of uniqueness for type-1 rules. $(\delta=\tau=0.5)$
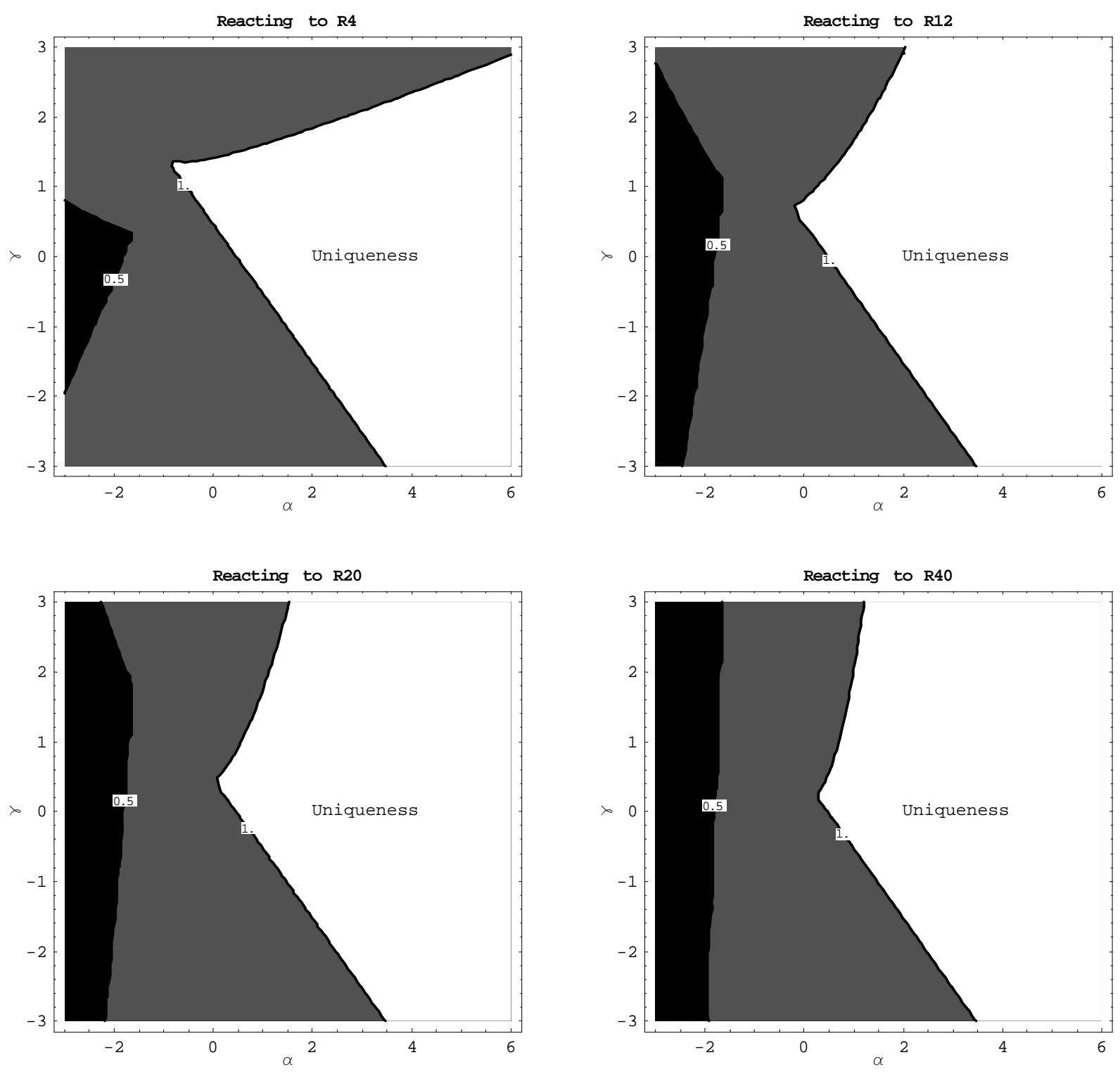
Figure 2: Regions of uniqueness for type-2 rules. $(\tau=0.5)$
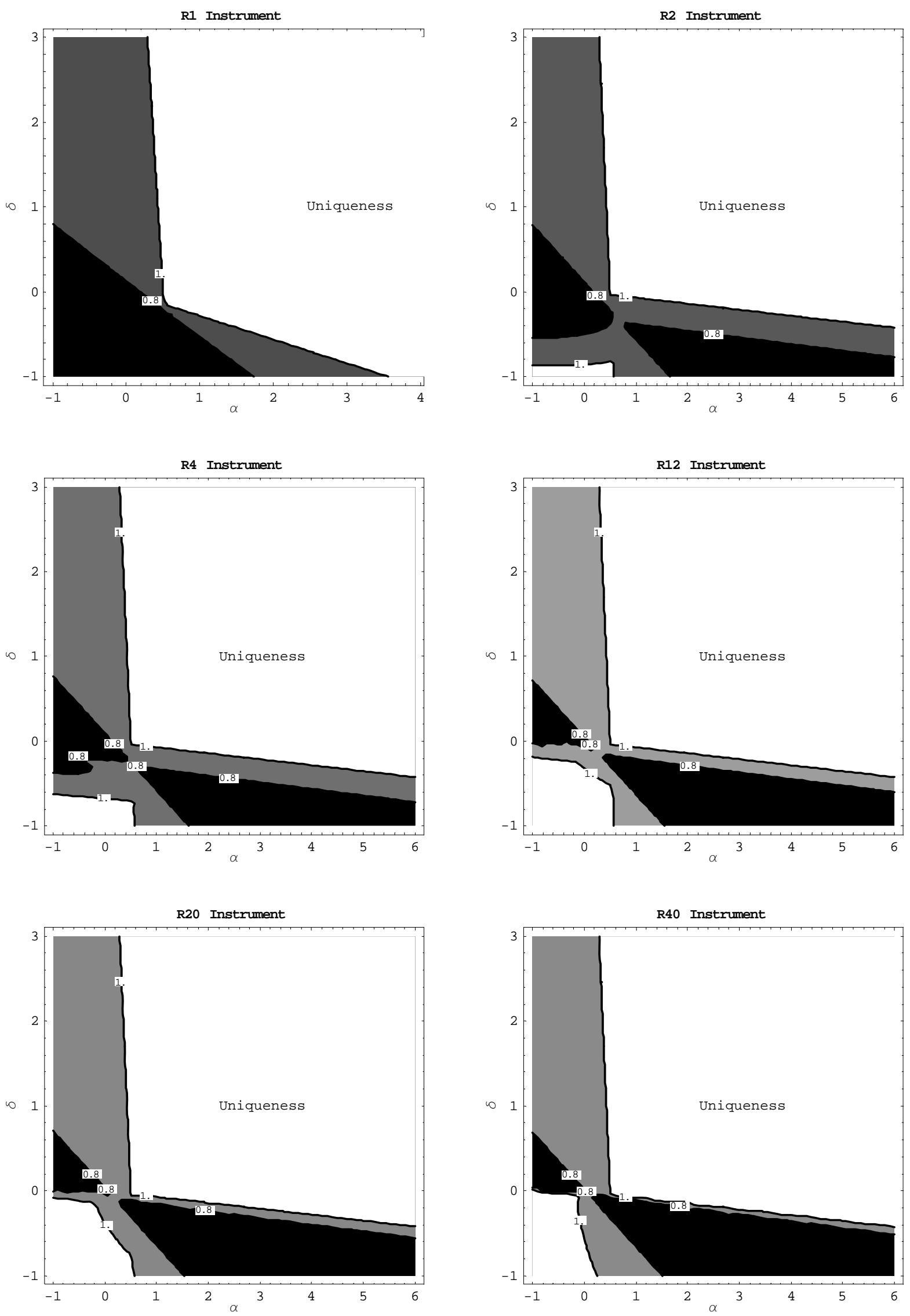
Table 1 : Optimal Type-1 rules

\begin{tabular}{|c|c|c|c|c|c|c|c|c|}
\hline \multicolumn{2}{|c|}{$\omega_{r}=0.1$} & \multirow{2}{*}{$\begin{array}{c}\text { Optimal } \\
\text { Rule }\end{array}$} & \multirow{2}{*}{$\begin{array}{c}\text { Standard } \\
\text { Rule }\end{array}$} & \multicolumn{5}{|c|}{ Type-1 Rules } \\
\hline & & & & R2 & R4 & R12 & R20 & R40 \\
\hline \multirow{4}{*}{$\omega_{x}=0.1$} & Loss & 0.9926 & 1.0032 & 1.0032 & 1.0032 & 1.0032 & 1.0032 & 1.0032 \\
\hline & Var_pi & 0.1015 & 0.1147 & 0.1147 & 0.1147 & 0.1147 & 0.1147 & 0.1147 \\
\hline & Var_x & 8.8961 & 8.8824 & 8.8824 & 8.8824 & 8.8824 & 8.8824 & 8.8824 \\
\hline & Var_r & 0.0150 & 0.0031 & 0.0031 & 0.0031 & 0.0031 & 0.0031 & 0.0031 \\
\hline \multirow{4}{*}{$\omega_{x}=1 / 3$} & Loss & 2.8191 & 2.8744 & 2.8744 & 2.8744 & 2.8744 & 2.8744 & 2.8744 \\
\hline & Var_pi & 0.4574 & 0.3616 & 0.3614 & 0.3614 & 0.3614 & 0.3614 & 0.3614 \\
\hline & Var_x & 7.0625 & 7.5377 & 7.5383 & 7.5383 & 7.5382 & 7.5383 & 7.5383 \\
\hline & Var_r & 0.0757 & 0.0027 & 0.0027 & 0.0027 & 0.0027 & 0.0027 & 0.0027 \\
\hline \multirow{4}{*}{$\omega_{x}=1$} & Loss & 6.7243 & 7.5900 & 7.5900 & 7.5900 & 7.5900 & 7.5900 & 7.5900 \\
\hline & Var_pi & 1.6088 & 0.8299 & 0.8299 & 0.8301 & 0.8299 & 0.8299 & 0.8299 \\
\hline & Var_x & 5.0405 & 6.7488 & 6.7488 & 6.7486 & 6.7488 & 6.7488 & 6.7488 \\
\hline & Var_r & 0.7504 & 0.1130 & 0.1130 & 0.1130 & 0.1130 & 0.1130 & 0.1130 \\
\hline \multirow{4}{*}{$\omega_{x}=3$} & Loss & 14.2980 & 19.5110 & 19.5110 & 19.5110 & 19.5110 & 19.5110 & 19.5110 \\
\hline & Var_pi & 4.8407 & 3.7726 & 3.7726 & 3.7725 & 3.7726 & 3.7726 & 3.7726 \\
\hline & Var_x & 3.0422 & 5.1710 & 5.1710 & 5.1711 & 5.1710 & 5.1710 & 5.1710 \\
\hline & Var_r & 3.3090 & 2.2525 & 2.2525 & 2.2524 & 2.2525 & 2.2525 & 2.2525 \\
\hline
\end{tabular}


Table 2 : Optimal Type-2 rules $(\omega \mathrm{r}=0.1)$

\begin{tabular}{|c|c|c|c|c|c|c|c|c|}
\hline \multicolumn{2}{|c|}{$\omega_{r}=0.1$} & \multirow{2}{*}{$\begin{array}{l}\text { Optimal } \\
\text { Rule }\end{array}$} & \multirow{2}{*}{$\begin{array}{c}\text { Standard } \\
\text { Rule }\end{array}$} & \multicolumn{5}{|c|}{ Type-2 Rules } \\
\hline & & & & R2 & R4 & R12 & R20 & R40 \\
\hline \multirow{4}{*}{$\omega_{x}=0.01$} & Loss & 0.1167 & 0.1180 & 0.1179 & 0.1177 & 0.1182 & 0.1189 & 0.1195 \\
\hline & Var_pi & 0.0039 & 0.0032 & 0.0032 & 0.0032 & 0.0033 & 0.0024 & 0.0012 \\
\hline & Var_x & 11.0347 & 11.2289 & 11.2218 & 11.2058 & 11.1868 & 11.2659 & 11.4064 \\
\hline & Var_r & 0.0252 & 0.0248 & 0.0245 & 0.0244 & 0.0307 & 0.0386 & 0.0423 \\
\hline \multirow{4}{*}{$\omega_{x}=0.05$} & Loss & 0.5287 & 0.5376 & 0.5374 & 0.5370 & 0.5359 & 0.5362 & 0.5377 \\
\hline & Var pi & 0.0396 & 0.0443 & 0.0440 & 0.0435 & 0.0426 & 0.0433 & 0.0453 \\
\hline & Var_x & 9.7381 & 9.8486 & 9.8494 & 9.8505 & 9.8377 & 9.8192 & 9.7952 \\
\hline & Var_r & 0.0216 & 0.0094 & 0.0095 & 0.0098 & 0.0138 & 0.0194 & 0.0262 \\
\hline \multirow{4}{*}{$\omega_{x}=0.1$} & Loss & 0.9926 & 1.0032 & 1.0032 & 1.0029 & 1.0028 & 1.0027 & 1.0035 \\
\hline & Var_pi & 0.1015 & 0.1147 & 0.1143 & 0.1134 & 0.1116 & 0.1097 & 0.1110 \\
\hline & Var_x & 8.8961 & 8.8824 & 8.8853 & 8.8917 & 8.9075 & 8.9230 & 8.9173 \\
\hline & Var_r & 0.0150 & 0.0031 & 0.0031 & 0.0033 & 0.0040 & 0.0063 & 0.0069 \\
\hline \multirow{4}{*}{$\omega_{x}=1 / 3$} & Loss & 2.8191 & 2.8744 & 2.8752 & 2.8766 & 2.8773 & 2.8775 & 2.8778 \\
\hline & Var_pi & 0.4574 & 0.3616 & 0.3593 & 0.3562 & 0.3556 & 0.3554 & 0.3515 \\
\hline & Var_x & 7.0625 & 7.5377 & 7.5472 & 7.5612 & 7.5651 & 7.5662 & 7.5789 \\
\hline & Var_r & 0.0757 & 0.0027 & 0.0019 & 0.0006 & 0.0000 & 0.0000 & 0.0000 \\
\hline \multirow{4}{*}{$\omega_{x}=1$} & Loss & 6.7243 & 7.5900 & 7.6189 & 7.6732 & 7.7088 & 7.7089 & 7.7105 \\
\hline & Var_pi & 1.6088 & 0.8299 & 0.7823 & 0.6832 & 0.5987 & 0.6066 & 0.6135 \\
\hline & Var_x & 5.0405 & 6.7488 & 6.8280 & 6.9865 & 7.1101 & 7.1023 & 7.0970 \\
\hline & Var_r & 0.7504 & 0.1130 & 0.0872 & 0.0347 & 0.0000 & 0.0000 & 0.0000 \\
\hline \multirow{4}{*}{$\omega_{x}=3$} & Loss & 14.2980 & 19.5110 & 19.8466 & 20.6461 & 21.8445 & 21.9581 & 22.0236 \\
\hline & Var_pi & 4.8407 & 3.7726 & 3.5856 & 3.1417 & 5.8654 & 6.0786 & 6.1891 \\
\hline & Var_x & 3.0422 & 5.1710 & 5.3491 & 5.7716 & 5.1613 & 5.1196 & 5.1001 \\
\hline & Var $r$ & 3.3090 & 2.2525 & 2.1369 & 1.8943 & 4.9512 & 5.2074 & 5.3430 \\
\hline
\end{tabular}


Table 3 : Optimal Type-2 rules $(\omega \mathrm{r}=1)$

\begin{tabular}{|c|c|c|c|c|c|c|c|c|}
\hline \multicolumn{2}{|c|}{$\omega_{r}=1$} & \multirow{2}{*}{$\begin{array}{l}\text { Optimal } \\
\text { Rule }\end{array}$} & \multirow{2}{*}{$\begin{array}{c}\text { Standard } \\
\text { Rule }\end{array}$} & \multicolumn{5}{|c|}{ Type-2 Rules } \\
\hline & & & & R2 & R4 & R12 & R20 & R40 \\
\hline \multirow{4}{*}{$\omega_{x}=0.01$} & Loss & 0.1280 & 0.1289 & 0.1288 & 0.1287 & 0.1306 & 0.1335 & 0.1366 \\
\hline & Var_pi & 0.0128 & 0.0129 & 0.0128 & 0.0127 & 0.0156 & 0.0199 & 0.0254 \\
\hline & Var_x & 10.9092 & 10.9984 & 10.9958 & 10.9874 & 10.9132 & 10.8553 & 10.7963 \\
\hline & Var_r & 0.0062 & 0.0061 & 0.0061 & 0.0061 & 0.0058 & 0.0050 & 0.0032 \\
\hline \multirow{4}{*}{$\omega_{x}=0.05$} & Loss & 0.5375 & 0.5419 & 0.5418 & 0.5415 & 0.5415 & 0.5426 & 0.5440 \\
\hline & Var_pi & 0.0479 & 0.0522 & 0.0520 & 0.0515 & 0.0522 & 0.0549 & 0.0584 \\
\hline & Var_x & 9.7043 & 9.7458 & 9.7472 & 9.7488 & 9.7300 & 9.7017 & 9.6733 \\
\hline & Var_r & 0.0044 & 0.0024 & 0.0024 & 0.0026 & 0.0028 & 0.0026 & 0.0018 \\
\hline \multirow{4}{*}{$\omega_{x}=0.1$} & Loss & 0.9993 & 1.0047 & 1.0046 & 1.0045 & 1.0044 & 1.0048 & 1.0053 \\
\hline & Var_pi & 0.1090 & 0.1183 & 0.1181 & 0.1175 & 0.1166 & 0.1175 & 0.1193 \\
\hline & Var_x & 8.8679 & 8.8555 & 8.8571 & 8.8607 & 8.8685 & 8.8638 & 8.8538 \\
\hline & Var_r & 0.0035 & 0.0008 & 0.0008 & 0.0009 & 0.0010 & 0.0009 & 0.0006 \\
\hline \multirow{4}{*}{$\omega_{x}=1 / 3$} & Loss & 2.8492 & 2.8757 & 2.8762 & 2.8769 & 2.8773 & 2.8778 & 2.8780 \\
\hline & Var_pi & 0.3916 & 0.3581 & 0.3572 & 0.3558 & 0.3555 & 0.3509 & 0.3553 \\
\hline & Var_x & 7.3225 & 7.5506 & 7.5554 & 7.5629 & 7.5656 & 7.5806 & 7.5684 \\
\hline & Var_r & 0.0167 & 0.0008 & 0.0005 & 0.0002 & 0.0000 & 0.0000 & 0.0000 \\
\hline \multirow{4}{*}{$\omega_{x}=1$} & Loss & 7.1171 & 7.6441 & 7.6601 & 7.6891 & 7.7070 & 7.7098 & 7.7953 \\
\hline & Var_pi & 1.1005 & 0.6977 & 0.6772 & 0.6367 & 0.6058 & 0.6064 & 0.5047 \\
\hline & Var_x & 5.7595 & 6.9144 & 6.9589 & 7.0434 & 7.1011 & 7.1034 & 7.2891 \\
\hline & Var_r & 0.2570 & 0.0320 & 0.0240 & 0.0090 & 0.0000 & 0.0000 & 0.0015 \\
\hline \multirow{4}{*}{$\omega_{x}=3$} & Loss & 16.3987 & 20.5962 & 20.8247 & 21.3184 & 21.7777 & 21.7844 & 21.7845 \\
\hline & Var_pi & 3.0671 & 1.8028 & 1.6506 & 1.2557 & 0.7568 & 0.7618 & 0.7485 \\
\hline & Var_x & 3.9136 & 6.0524 & 6.2104 & 6.5889 & 7.0070 & 7.0075 & 7.0120 \\
\hline & Var_r & 1.5907 & 0.6364 & 0.5428 & 0.2960 & 0.0000 & 0.0000 & 0.0000 \\
\hline
\end{tabular}


Figure 3 : Impulse Responses for $\pi$ and $x$. Standard Taylor Rule and type 1 and 2 rules for R12 and R40. ( $\tau=0.6, \alpha=0.6, \delta=0.1$ and $\gamma=0.5$ )
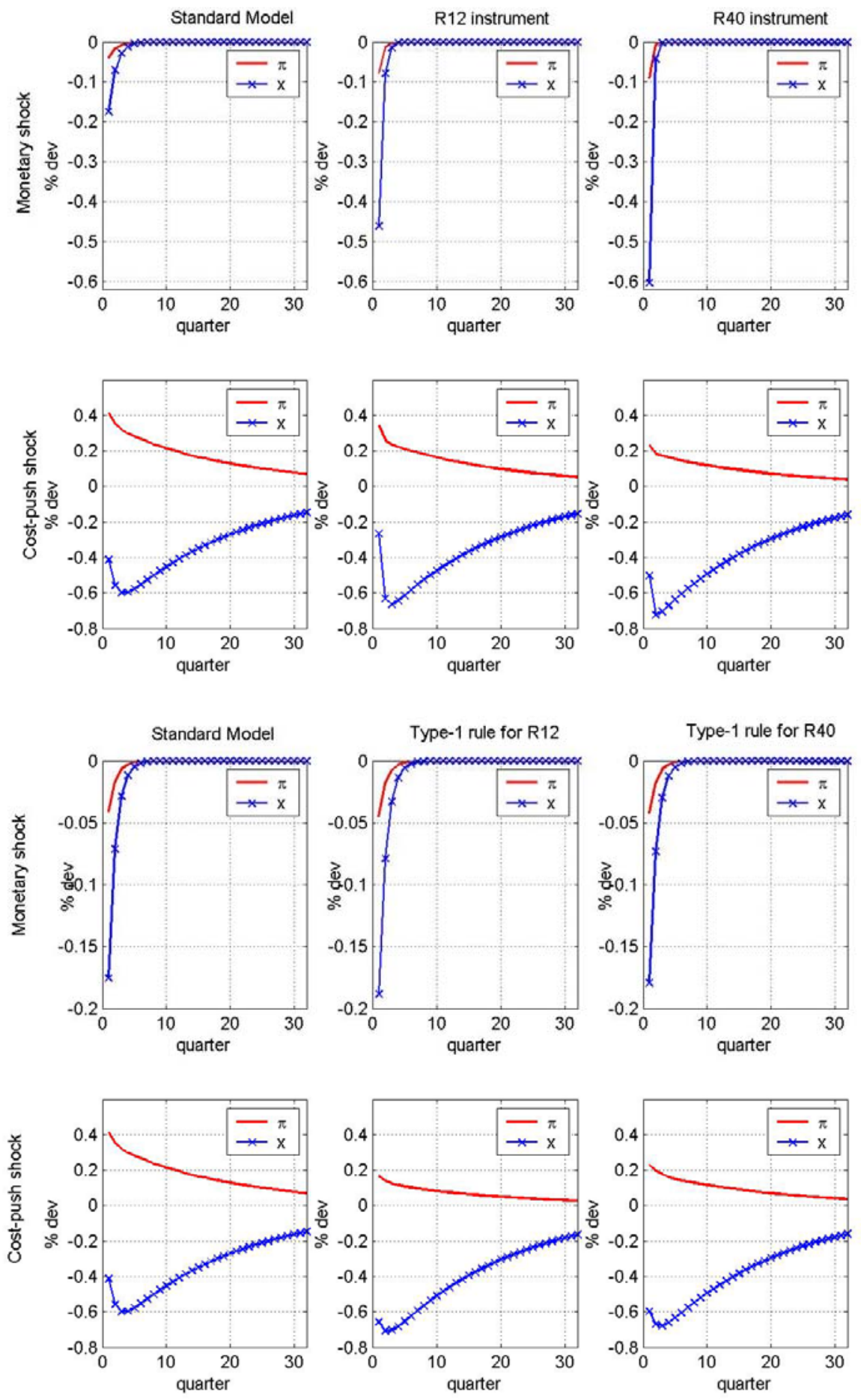
Figure 4: Optimal Policy for Type-2 rules. Maturity trade-off.

Panel A: $(\omega \mathrm{x}=0.1$ and $\omega \mathrm{r}=0.1)$
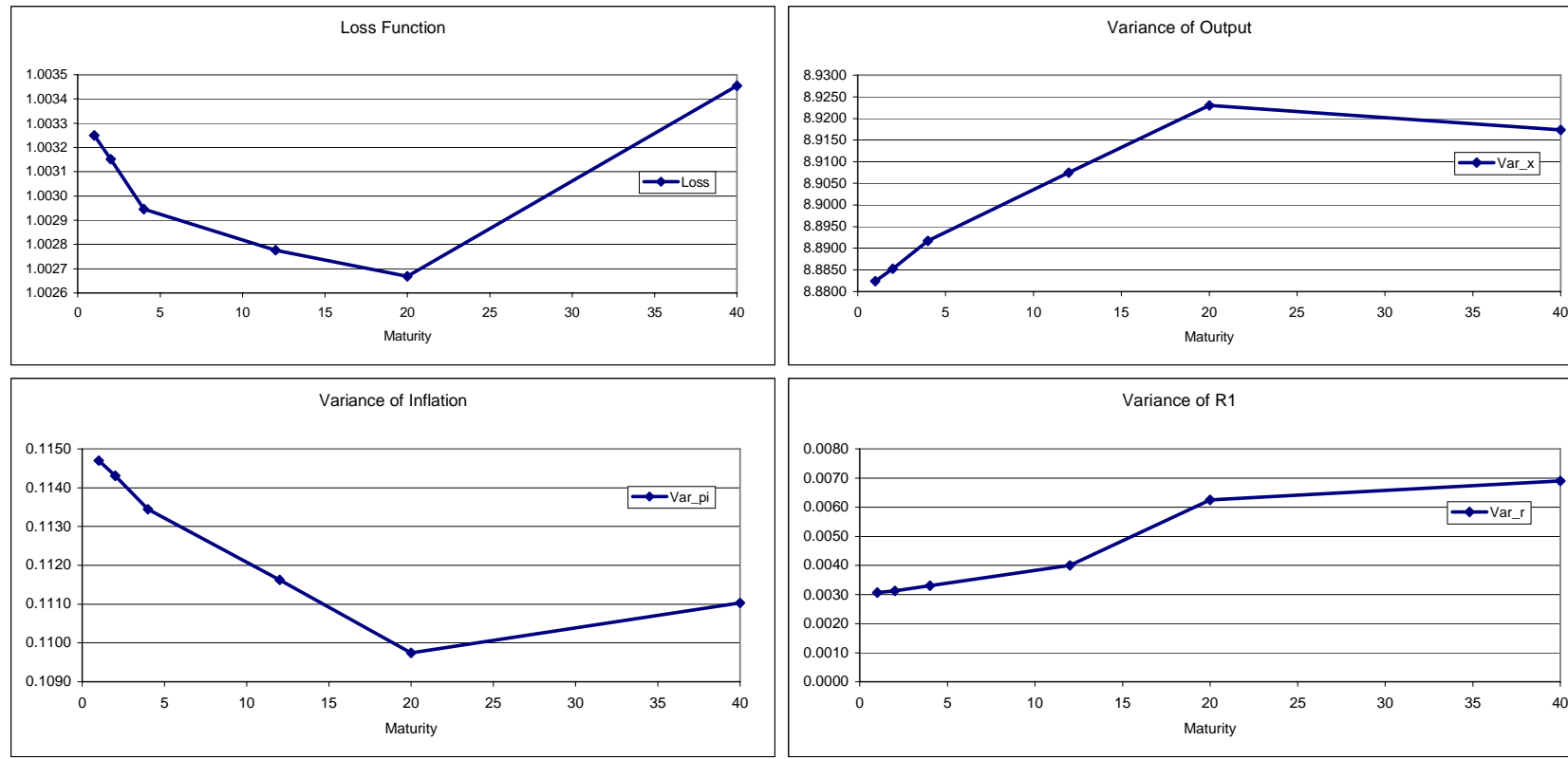

Panel B : $(\omega \mathrm{x}=3$ and $\omega \mathrm{r}=0.1)$
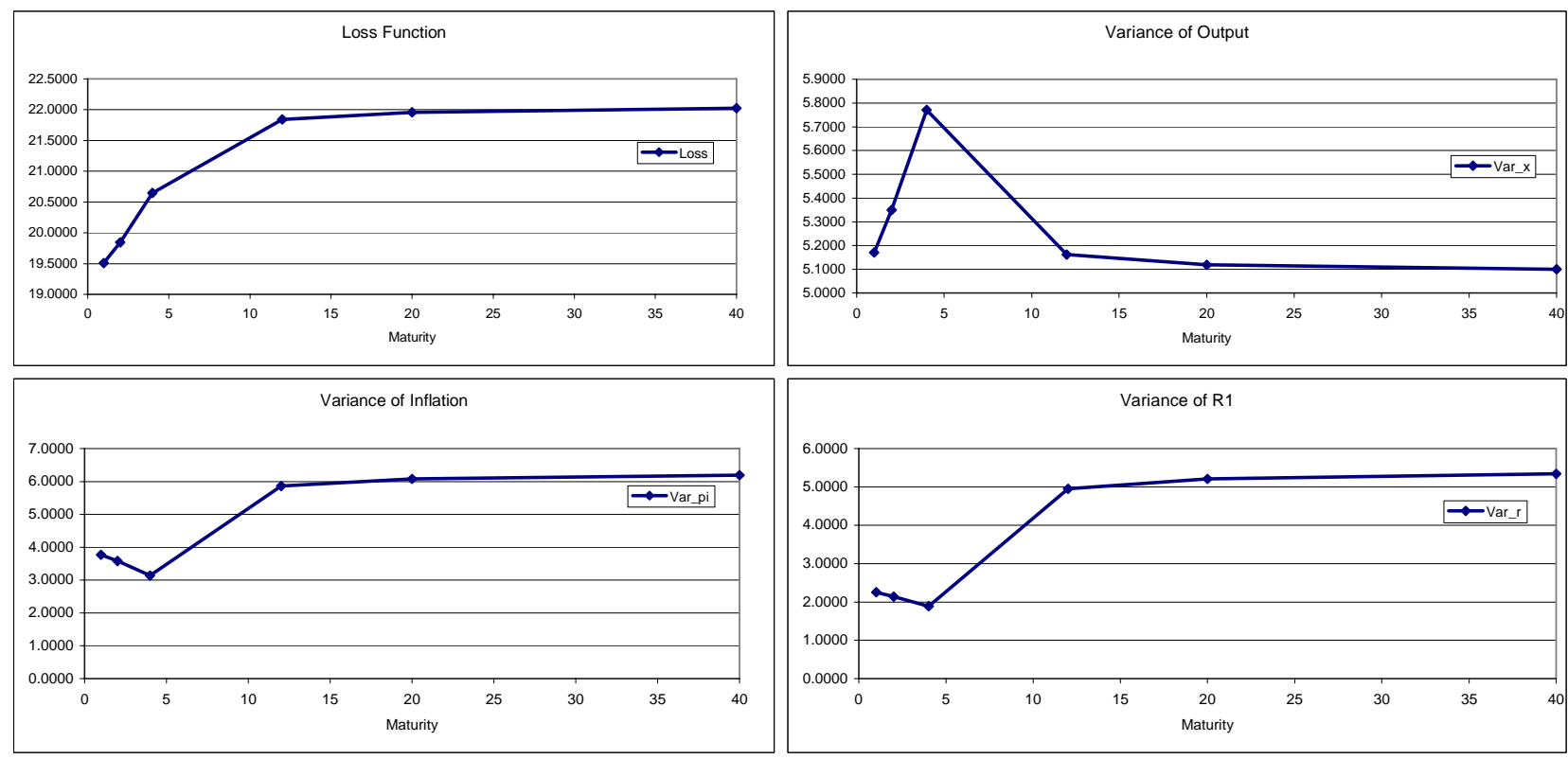
Figure 5: Comparing type-2 rules: Varying $\delta .(\omega \mathrm{x}=3$ y $\omega \mathrm{r}=0.1)$
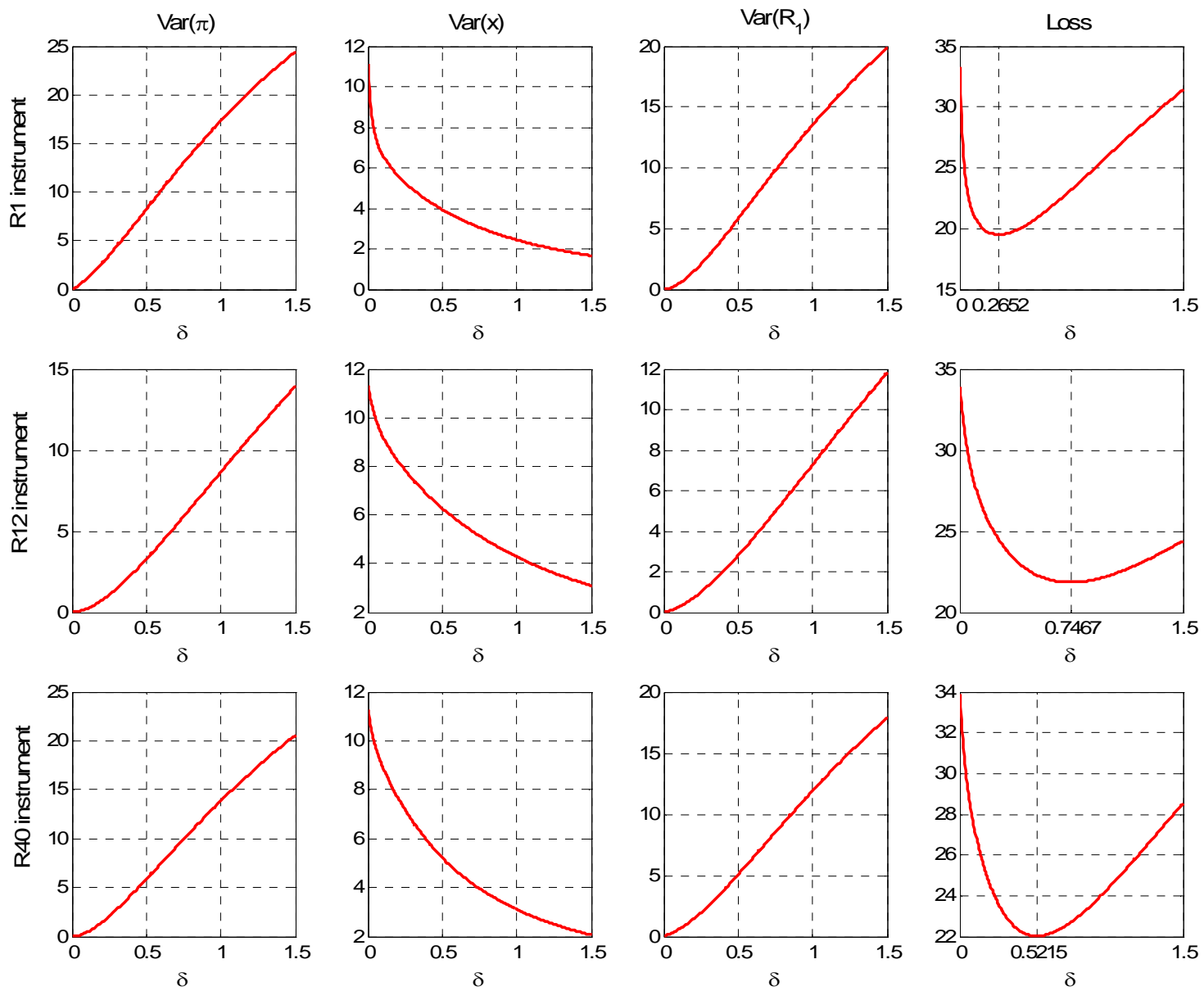